\title{
3-Phenyl-2,7-naphthyridin-1(2H)-one as a New Fluorogenic Reagent for Epoxides and Its Application to Determination of Trichothecene Mycotoxins
}

\author{
Akira Sano, Yoshihiro Asabe and Shoji Takitani \\ Faculty of Pharmaceutical Sciences, Science University of Tokyo, Ichigaya-funagawara-machi, \\ Shinjuku, Tokyo 162
}

\begin{abstract}
A fluorescence reaction of epoxides with 3-phenyl-2,7-naphthyridin-1(2H)-one (PNO) is described. Common epoxides and 12,13-epoxytrichothecenes gave a green fluorescence $\left(\lambda_{\text {ex }} 441-467 \mathrm{~nm}\right.$ and $\lambda_{\text {em }} 506-510 \mathrm{~nm}$ ) after reaction with $\mathrm{PNO}$ at $120^{\circ} \mathrm{C}$ for $90 \mathrm{~min}$ in 1,2-ethanediol/2-methoxyethanol mixture for the former and at $150^{\circ} \mathrm{C}$ for $30 \mathrm{~min}$ on a solid phase for the latter, respectively, and followed by addition of $\mathrm{N}, \mathrm{N}$-dimethylformamide in both the cases. By the proposed methods, as little as $20-30 \mathrm{pmol}$ of common epoxides and $64-85 \mathrm{pmol}$ of trichothecenes could be determined with relative standard deviations of ranges $1.7-4.3 \%$ and $4.8-8.6 \%$, respectively.
\end{abstract}

Keywords Epoxides, trichothecene mycotoxins, alkylating agents, fluorescence reaction, 3-phenyl-2,7-naphthyridin-1(2H)-one

Trichothecene mycotoxins, having a characteristic 12,13-epoxytrichothec-9-ene structure, are naturally occurring fungal toxic sesquiterpenoids produced by various species such as Fusarium, Myrothecium, Trichothecium and Cephalosporium. There have been many reports that these toxins cause a number of illnesses in man and animals, and trichothecenes are also found in foods and feeds in Japan, United States of America, Canada, England and several other countries. ${ }^{1,2}$ Thus various following methods have been developed for determining trichothecenes: gas chromatography ${ }^{3-5}$, thin-layer chromatography ${ }^{6-8}$, high performance liquid chromatography ${ }^{9,10}$, polarography ${ }^{11}$ and immunoassay. ${ }^{12,13}$ Gas chromatography is highly sensitive and is the technique most used for deter-

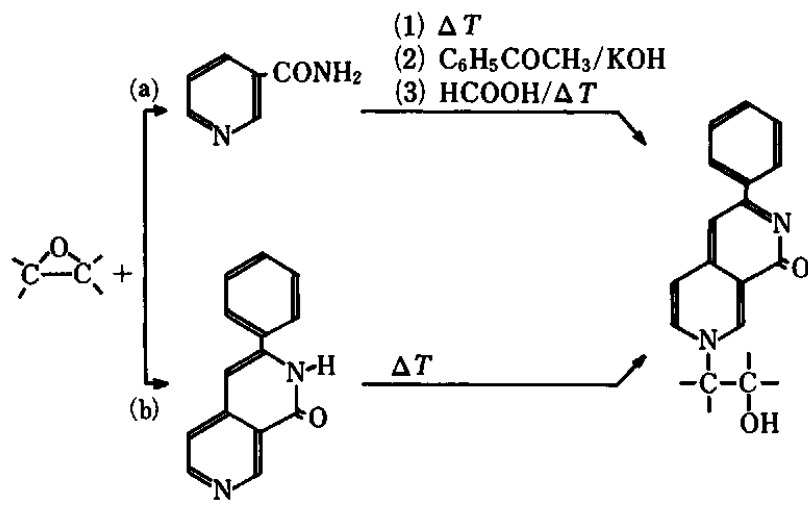

Fig. 1 Reaction of epoxides with nicotinamide (a) and PNO (b). mination of trichothecenes. But erroneous identification can sometimes occur ${ }^{14,15}$, although, the use of expensive mass spectrometer as a detector can avoid this problem.

Sub-nanomol amounts of some epoxides could be determined fluorometrically by their reaction with nicotinamide and active methylenes (NA method) ${ }^{16,17}$, and it has been confirmed that the fluorophore has a 2,7-naphthyridine structure. ${ }^{17,18}$ And the NA method has been applied to the fluorodensitometric determination of trichothecenes. ${ }^{7}$

Although, in the NA method sensitivity and fluorophore stability were satisfactory, the experimental procedures were rather complicated because of the necessity of multi-reaction steps. If 3-phenyl-2,7naphthyridin-1(2H)-one (PNO), which corresponds to the de-alkylated derivative of the fluorophore resulted by the NA method, is used as a reagent, epoxides are expected to give the same reaction product with the NA method by only one step (Fig. 1). Therefore, under the such consideration, the present study aimed at establishing a simple fluorometric method (PNO method) for determining common epoxides with PNO and then, we attempted to apply the PNO method for determining trichothecene mycotoxins.

\section{Experimental}

\section{Preparation of $P N O$}

PNO was prepared according to the method of 
Kröhnke et al. ${ }^{19}$ The product was further purified by repeated recrystallization from ethanol as white needles: mp. $234.5-235.5^{\circ} \mathrm{C}$ (uncorrected; $237-239^{\circ} \mathrm{C}^{19}$, $239-239.5^{\circ} \mathrm{C}^{20}$ ). Anal. Calcd for $\mathrm{C}_{14} \mathrm{H}_{10} \mathrm{~N}_{2} \mathrm{O}$ : C, 75.70; H, 4.54; N, 12.61. Found: C, 75.70; H, 4.61; N, 12.56 . Although Kröhnke et al. reported that PNO had a 3phenyl-2,7-naphthyridin-1(4H)-one structure, this structure has been corrected to 3-phenyl-2,7-naphthyridin1(2H)-one by Bobbitt et al. ${ }^{20}$

\section{Chemicals}

PNO was used as a $0.5 \%(\mathrm{w} / \mathrm{v})$ solution in $1,2-$ ethanediol/2-methoxyethanol $(1: 1)$ and a $0.1 \%(w / v)$ solution in ethanol. Stock standard solutions of common epoxides, alkyl halides (Tokyo Kasei Co.), $O$ p-nitrophenyl phosphorothioate (parathion, purchased from Wako Pure Chemical Industry Ltd.), $p$-[bis-(2chloroethyl)amino]-L-phenylalanine (melphalan), 1,6dibromo-1,6-dideoxy-D-mannitol (mitobronitol, purchased from Sigma Chemical Co.), 1,4-butanediol dimethanesulfonate (busulfan, supplied by Takeda Pharmaceutical Co.), 2-[bis-(2-chloroethyl)amino] tetrahydro-2H-1,3,2-oxazaphosphorine 2-oxide (cyclophosphamide, supplied by Shionogi Pharmaceutical Co.), 1(4-amino-2-methyl-5-pyrimidinyl)methyl-3-(2-chloroethyl)-3-nitrosourea hydrochloride (nimustine, supplied by Sankyo Pharmaceutical Co.) and tris-(1-aziridinyl)phosphine sulfide (thiotepa, supplied by Sumitomo Chemical Co.) were prepared at $2-10 \mathrm{mM}$ concentrations in 2-methoxyethanol.

The trichothecene mycotoxins used in this study, $4 \beta$ -

Table 1 Structures of trichothecene mycotoxins

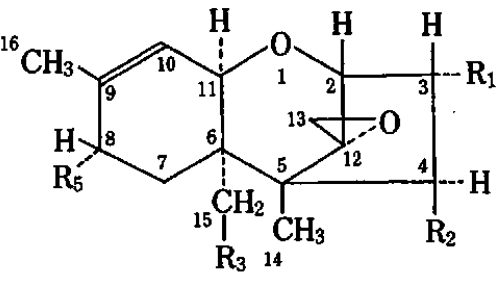

\begin{tabular}{lcccc}
\hline & $\mathbf{R}_{1}$ & $\mathbf{R}_{2}$ & $\mathbf{R}_{3}$ & $\mathbf{R}_{5}$ \\
\hline T-2 toxin & $\mathrm{OH}$ & $\mathrm{OCOCH}_{3}$ & $\mathrm{OCOCH}_{3}$ & $\mathrm{OCOCH}_{2} \mathrm{CH}\left(\mathrm{CH}_{3}\right)_{2}$ \\
$\begin{array}{l}\text { Diacetoxy- } \\
\text { scirpenol }\end{array}$ & $\mathrm{OH}$ & $\mathrm{OCOCH}_{3}$ & $\mathrm{OCOCH}_{3}$ & $\mathbf{H}$ \\
\hline
\end{tabular}

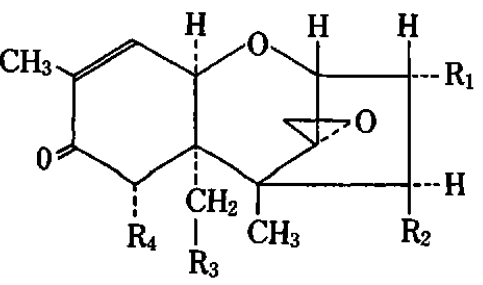

\begin{tabular}{lcccc}
\hline & $\mathbf{R}_{1}$ & $\mathbf{R}_{2}$ & $\mathbf{R}_{3}$ & $\mathbf{R}_{4}$ \\
\hline Fusarenone-X & $\mathrm{OH}$ & $\mathrm{OCOCH}_{3}$ & $\mathrm{OH}$ & $\mathrm{OH}$ \\
Deoxynivalenol & $\mathrm{OH}$ & $\mathbf{H}$ & $\mathrm{OH}$ & $\mathrm{OH}$ \\
Nivalenol & $\mathrm{OH}$ & $\mathrm{OH}$ & $\mathrm{OH}$ & $\mathrm{OH}$ \\
\hline
\end{tabular}

hydroxy-3 $\alpha, 15$-diacetoxy-8 $\alpha$-(3-methylbutyryloxy)-12,13epoxytrichothec-9-ene (T-2 toxin), $3 \alpha$-hydroxy-4 $\beta, 15-$ diacetoxy-12,13-epoxytrichothec-9-ene (diacetoxyscirpenol), $3 \alpha, 7 \alpha, 15$-trihydroxy-4 $\beta$-acetoxy-12,13-epoxytrichothec-9-en-8-one (fusarenone-X), $3 \alpha, 7 \alpha, 15$-trihydroxy12,13-epoxytrichothec-9-en-8-one (deoxynivalenol) and $3 \alpha, 4 \beta, 7 \alpha, 15$-tetrahydroxy-12,13-epoxytrichothec-9-en-8one (nivalenol) are purchased from Wako Pure Chemical lndustry Ltd. These structures were listed in Table 1. Stock standard solutions of trichothecenes were prepared at 1-2 mM concentrations in methanol.

Except for the use for PNO preparation, other chemicals used were of analytical-reagent grade.

\section{Apparatus}

A Shimadzu RF-502 spectrofluorometer equipped with a xenon lamp was used with a $4 \times 10 \mathrm{~mm}$ quartz cell at room temperature. The spectral bandwidths were $5 \mathrm{~nm}$ (excitation) and $4 \mathrm{~nm}$ (emission). All fluorescence excitation and emission spectra are uncorrected. A dry block heater (DRI-BLOCK DB$3 \mathrm{H}, \mathrm{M} \& \mathrm{~S}$ Instruments) was used for the reaction.

\section{Procedure for determination of common epoxides}

To a $10 \mu \mathrm{l}$ of sample solution in a $1.5-\mathrm{ml}$ glassstoppered test tube, add $100 \mu \mathrm{l}$ of the $0.5 \%$ PNO solution, and place the tube in a block heater at $120^{\circ} \mathrm{C}$ for $90 \mathrm{~min}$. After cooling it to room temperature, dilute the solution with $500 \mu \mathrm{l}$ of $\mathrm{N}, \mathrm{N}$-dimethylformamide (DMF) and measure the fluorescence intensity at respective excitation and emission wavelengths.

\section{Procedure for determination of trichothecene mycotoxins}

Pipette a $10 \mu \mathrm{l}$ of sample solution in $1.5-\mathrm{ml}$ glassstoppered test tube and evaporate to dryness. Add to it $20 \mu \mathrm{l}$ of the $0.1 \%$ PNO solution and evaporate to dryness again. Place the tube in a block heater at $150^{\circ} \mathrm{C}$ for $30 \mathrm{~min}$. After cooling it to room temperature, add $600 \mu \mathrm{l}$ of DMF to the mixture and measure the fluorescence intensity with excitation at $467 \mathrm{~nm}$ and emission at $507 \mathrm{~nm}$.

\section{Results and Discussion}

\section{Determination of common epoxides}

Experimental conditions were examined by using 1,2-epoxy-3-phenoxypropane (EPP) as a representative sample of common epoxides.

2-Methoxyethanol and 1,2-ethanediol/2-methoxyethanol mixed solvent were selected for sample and PNO, respectively, because of their excellent features with regards to non-volatility, solubility of PNO and the fluorescence intensity of the resulting products. A ratio of $1: 1$ was selected as the optimal value for the 1,2-ethanediol/2-methoxyethanol mixture.

The reaction product of EPP showed a blue fluorescence (excitation at $392 \mathrm{~nm}$ and emission at 434 
Table 2 Effect of dilution ${ }^{\mathrm{a}}$

\begin{tabular}{lcccc}
\hline \multirow{2}{*}{ Solvent } & \multicolumn{2}{c}{$\lambda_{\max } / \mathrm{nm}$} & & Test/ \\
\cline { 2 - 4 } & $\begin{array}{l}\text { Excita- } \\
\text { tion }\end{array}$ & $\begin{array}{l}\text { Emis- } \\
\text { sion }\end{array}$ & RFI & $\begin{array}{l}\text { Testank } \\
\text { blann }\end{array}$ \\
\hline No dilution & 392 & 434 & 515 & 0.8 \\
$N, N$-dimethyl- & & & & \\
$\quad$ formamide (DMF) & 451 & 507 & 100 & 66 \\
Ethanol & 428 & 500 & 91 & 33 \\
Dioxane & 421 & 490 & 90 & 40 \\
2-Methoxyethanol & 428 & 500 & 87 & 31 \\
Dimethylsulfoxide & 451 & 507 & 80 & 46 \\
Acetone & 435 & 506 & 35 & 28 \\
\hline
\end{tabular}

a. EPP (1 nmol) was reacted with the same manner as described in the standard procedure, and then diluted with $500 \mu l$ of each solvent.

b. Relative fluorescence intensity; the intensity in DMF is arbitrarily taken as 100 .

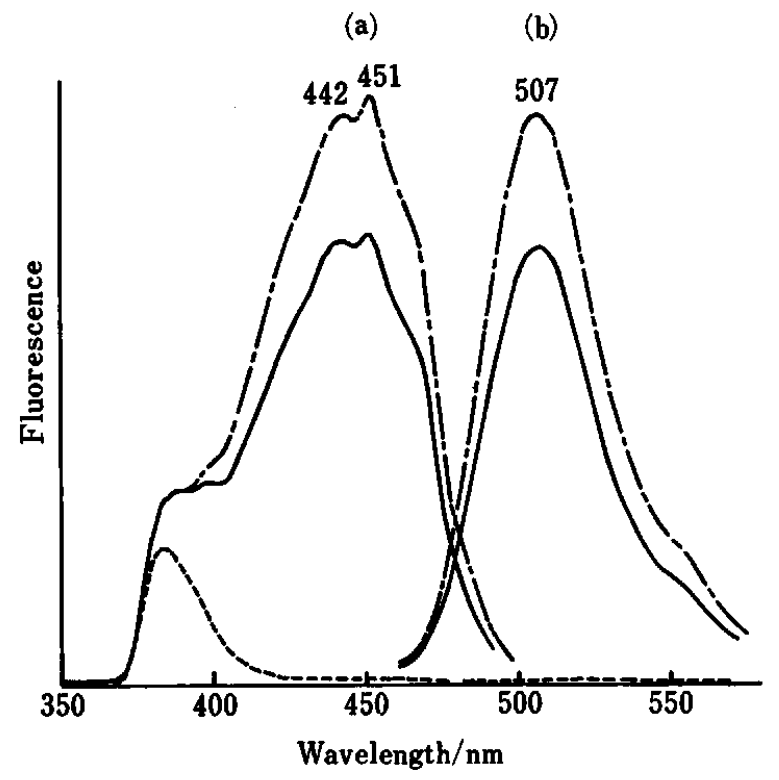

Fig. 2 Fluorescence excitation and emission spectra of the reaction mixture of EPP and the reagent blank obtained by the standard procedure, and the isolated fluorophore in the NA method. ${ }^{17}$ (a), Excitation spectra; (b), emission spectra. Reaction mixture obtained from $1 \mathrm{nmol}$ of EPP (-); the reagent blank $(---) ; 1$ nmol of the fluorophore dissolved in the reagent blank solution (-- $)$.

nm), while PNO itself showed a blue-purple fluorescence (excitation at $384 \mathrm{~nm}$ and emission at $426 \mathrm{~nm}$ ). But when DMF was used as a diluent, the fluorescence maximum of the reaction product shifted to excitation at ca. $450 \mathrm{~nm}$ and emission at ca. $500 \mathrm{~nm}$, while PNO itself was not affected. DMF was chosen as diluent because it gave a lower background signal as well as a higher fluorescence intensity of the fluorophore (Table 2), and also because of the stability of the fluorophore. The fluorescence was stable at least $2 \mathrm{~h}$ at room

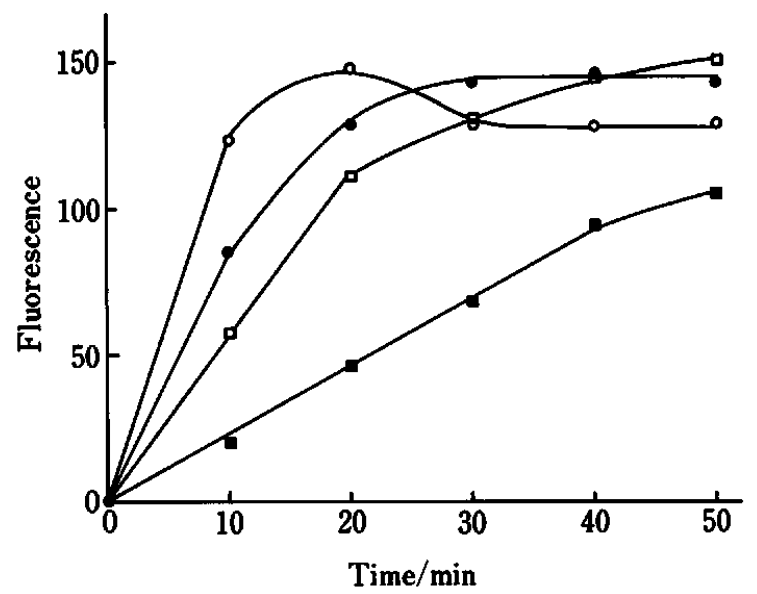

Fig. 3 Effect of reaction temperature and time on the reaction of deoxynivalenol (1.7 nmol) with PNO: (a) $130^{\circ} \mathrm{C}$; ( $\left.\square\right) 140^{\circ} \mathrm{C}$; (O) $150^{\circ} \mathrm{C}$; (O) $160^{\circ} \mathrm{C}$.

temperature.

The effect of PNO concentration on the fluorescence intensity was examined. The fluorescence intensity was increased from 0.1 to $0.3 \%$, then slowly up to the saturated concentration ( $c a .0 .55 \%$ ). A $0.5 \%$ solution was used in the present study.

The relationship between fluorescence intensity and reaction time was studied in the temperature range $100-120^{\circ} \mathrm{C}$. Almost constant intensity was obtained after heating at $120^{\circ} \mathrm{C}$ for $80 \mathrm{~min}$, but in the temperature below $110^{\circ} \mathrm{C}$, the reaction was incomplete even if after $2 \mathrm{~h}$. Thus reaction at $120^{\circ} \mathrm{C}$ for $90 \mathrm{~min}$ was selected.

The reaction product of EPP obtained by the proposed method and the isolated fluorophore in the NA method ${ }^{17}$ were submitted to silica gel thin-layer chromatography ${ }^{17}$ [solvent system: acetone-methanolformic acid (17:2:1)]; every blue fluorescent spot showed the same $R_{\mathrm{f}}$ value $\left(R_{\mathrm{f}} \mathbf{0 . 3 3}\right)$. The fluorescence spectra of the isolated fluorophore in the NA method dissolved in a blank solution obtained by the present method was also identical with those obtained by the reaction of EPP with PNO (Fig. 2). Thus, it could be confirmed that the same naphthyridine derivative was produced in both the methods. The reaction yield of EPP could be estimated to be $74 \%$ by comparison with both of the fluorescence intensities.

The fluorescence characteristics and their intensities of common epoxides and other some alkylating agents such as alkyl halides, antitumour agents and organophosphate are given in Table 3.

Linear calibration curves were obtained over the concentration ranges of $0.02-2 \mathrm{nmol} / 10 \mu \mathrm{l}$ for EPP and $0.03-3 \mathrm{nmol} / 10 \mu \mathrm{l}$ for 1,2-(epoxyethyl)benzene (EEB). The relative standard deviations (R.S.D., $n=10$ ) were $3.7 \%$ at $0.05 \mathrm{nmol}$ and $1.7 \%$ at $1 \mathrm{nmol}$ for EPP and $4.3 \%$ at $0.08 \mathrm{nmol}$ and $2.6 \%$ at $2 \mathrm{nmol}$ for EEB. When the NA method ${ }^{17}$ was carried out the same sample volume with the PNO method, the reproduc- 
Table 3 Relative fluorescence intensities of epoxides and other alkylating agents

\begin{tabular}{|c|c|c|c|}
\hline \multirow[b]{2}{*}{ Compounda } & \multicolumn{2}{|c|}{$\lambda_{\max } / \mathrm{nm}$} & \multirow[b]{2}{*}{ RFIb } \\
\hline & $\begin{array}{l}\text { Excita- } \\
\text { tion }\end{array}$ & $\begin{array}{l}\text { Emis- } \\
\text { sion }\end{array}$ & \\
\hline 1,2-Epoxyoctane & 441 & 506 & 17 \\
\hline 1,2-Epoxydecane & 441 & 506 & 28 \\
\hline 1,2-Epoxytetradecane & 441 & 506 & 42 \\
\hline 1,2,3,4-Diepoxybutane & 451 & 508 & 124 \\
\hline 1,2-(Epoxyethyl)benzene (EEB) & 451 & 507 & 50 \\
\hline 1,2-Epoxy-3-chloropropane & 451 & 510 & 40 \\
\hline 1,2-Epoxy-3,3,3-trichloropropane & 451 & 508 & 68 \\
\hline 1,2-Epoxy-3-phenoxypropane (EPP) & 451 & 507 & 100 \\
\hline 1,2-Epoxy-3-butoxypropane & 451 & 507 & 49 \\
\hline 1,2-Epoxy-3-methoxypropane & 451 & 507 & 30 \\
\hline 1,2-Epoxycyclohexane & 442 & 506 & 3. \\
\hline 1,2-Epoxycyclododecane & 442 & 509 & $\mathbf{0 .}$ \\
\hline 1-Chlorohexane & 442 & 508 & 0.3 \\
\hline 1-Bromohexane & 441 & 508 & 4.9 \\
\hline 1-Iodohexane & 441 & 508 & 11 \\
\hline Busulfan & 440 & 508 & 59. \\
\hline Cyclophosphamide & 440 & 507 & 33 \\
\hline Melphalan & 450 & 511 & 27 \\
\hline Mitobronitol & 440 & 506 & 82 \\
\hline Nimustine & 440 & 507 & 9. \\
\hline Thiotepa & 440 & 507 & 72 \\
\hline Parathion & 440 & 507 & 6.0 \\
\hline
\end{tabular}

a. Each compound $(2 \mathrm{nmol})$ was treated in the same manner as in the standard procedure.

b. Relative fluorescence intensity; the intensity from EPP is arbitrarily taken as 100 .

Table 4 Relative fluorescence intensities of trichothecene mycotoxins

\begin{tabular}{lccc}
\hline \multirow{2}{*}{ Compound } & \multicolumn{2}{c}{$\lambda_{\max } / \mathrm{nm}$} & \multirow{2}{*}{ RFI $^{\mathrm{b}}$} \\
\cline { 2 - 3 } & Excitation & Emission & \\
\hline T-2 toxin & 467 & 507 & 178 \\
Diacetoxyscirpenol & 467 & 508 & 140 \\
Fusarenone-X & 467 & 506 & 122 \\
Deoxynivalenol & 467 & 507 & 100 \\
Nivalenol & 467 & 507 & 119 \\
\hline
\end{tabular}

a. Each compound $(0.43-0.68 \mathrm{nmol})$ was treated in the same manner as in the standard procedure.

b. Relative fluorescence intensity; the intensity from deoxynivalenol is arbitrarily taken as $\mathbf{1 0 0}$.

ibilities were inferior to the PNO method. Therefore, PNO seems to be useful reagent for the fluorometric analysis of common epoxides.

\section{Determination of trichothecene mycotoxins}

In preliminary experiments, it was found that the direct application of the above method to the determination of trichothecenes was difficult because of less reactivity of these compounds (below $1 \%$ of the fluorescence intensity of EPP). Therefore, we tried a solid phase reaction. The reaction conditions were examined by using deoxynivalenol because it was most important one among trichothecene mycotoxins.

When the reaction of deoxynivalenol with PNO was carried out with evaporation after mixing with sample and reagent, reproducibilities of the results were unsatisfactory. The each of evaporation steps was necessary. Changes in the concentration of the PNO solution from $0.03-0.15 \%$ had no effect on the fluorescence intensity; therefore, the $0.1 \%$ solution was chosen.

The relationship between fluorescence intensity and reaction time was studied in the temperature range $130-160^{\circ} \mathrm{C}$. The best result was obtained when reaction was done at $150^{\circ} \mathrm{C}$ and constant fluorescence intensity was obtained after 30-50 min (Fig. 3), $30 \mathrm{~min}$ being convenient.

The fluorescence characteristics and their intensities of trichothecenes are summarized in Table 4.

The calibration curves were constructed for deoxynivalenol and nivalenol. The fluorescence intensities were proportional to the sample concentration in the range $0.085-1.7 \mathrm{nmol} / 10 \mu \mathrm{l}(25-500 \mathrm{ng} / 10 \mu \mathrm{l})$ for the former and $0.064-0.64 \mathrm{nmol} / 10 \mu \mathrm{l}(20-200 \mathrm{ng} / 10$ $\mu$ l) for the latter. The R. S. D. $(n=10)$ were $4.8 \%$ at $0.17 \mathrm{nmol}$ and $5.8 \%$ at $1.4 \mathrm{nmol}$ for deoxynivalenol and $8.6 \%$ at $0.16 \mathrm{nmol}$ and $6.1 \%$ at $0.64 \mathrm{nmol}$ for nivalenol.

Finally, our method was applied to the determination of deoxynivalenol in spiked corn samples. The clean-up method of Visconti et al." was used with slight modification in several points: re-extraction of deoxynivalenol from aqueous methanol was performed by ethyl acetate instead of chloroform; preparative thin-layer chromatography was carried out by using $10 \times 20 \mathrm{~cm}$ pre-coated TLC plates silica gel $F_{254}$ with concentration zone $(0.25 \mathrm{~mm}$ thickness, E. Merck) and with a solvent system chloroform-acetone-2-propanol $(8: 1: 1){ }^{8}$ The toxin band $\left(R_{\mathrm{f}} 0.43-0.54\right)$ was scraped off. The original corn was treated in the same manner and the fluorescence intensity resulted from the band corresponding to deoxynivalenol was used as a blank value. Deoxynivalenol was determined according to the standard addition method. The recovery in the method was found to be $54 \pm 5 \%(n=3)$ at deoxynivalenol concentration level of $1 \mathrm{ppm}$. Detection limit of deoxynivalenol for overall procedure was about 0.4 ppm for a sample size $50 \mathrm{~g}$; the higher detection limit resulted by the higher background fluorescence. But in preliminary examination, an additional clean-up step by using Sep-Pak florisil cartridges (Waters Associates) or cyano extraction column (J. T. Baker Chemical Co. $)^{21}$ was effective to eliminate the interfering substances. Further studies of clean-up procedure are in progress as the next study.

\section{References}

1. Y. Ueno, Ed., "Developments in Food Science 4; Trichothecenes-Chemical, Biochemical and Toxicological 
Aspects", Kodansha, Tokyo/Elsevier, Amsterdam (1983).

2. H. Kurata and Y. Ueno, Eds., "Developments in Food Science 7; Toxigenic Fungi-Their Toxins and Health Hazard", Kodansha, Tokyo/Elsevier, Amsterdam (1984).

3. H. Kamimura, M. Nishijima, K. Yasuda, K. Saito, A. Ibe, T. Nagayama, H. Ushiyama and Y. Naoi, J. Assoc. Off. Anal. Chem., 64, 1067 (1981).

4. P. M. Scott, P.-Y. Lau and S. R. Kanhere, J. Assoc. Off. Anal. Chem., 64, 1364 (1981).

5. T. Tanaka, A. Hasegawa, Y. Matsuki, K. Ishii and Y. Ueno, Food Addit. Contam., 2, 125 (1985).

6. S. Takitani, Y. Asabe, T. Kato, M. Suzuki and Y. Ueno, J. Chromatogr., 172, 335 (1979).

7. A. Sano, Y. Asabe, S. Takitani and Y. Ueno, J. Chromatogr., 235, 257 (1982).

8. M. W. Trucksess, S. Nesheim and R. M. Eppley, J. Assoc. Off. Anal. Chem., 67, 40 (1984).

9. A. Visconti and A. Bottalico, Chromatographia, 17, 97 (1983).

10. H. L. Chang, J. W. DeVries, P. A. Larson and H. H. Patel, J. Assoc. Off. Anal. Chem., 67, 52 (1984).

11. A. Visconti, A. Bottalico, F. Palmisano and P. G. Zambonin, Anal. Chim. Acta, 159, 111 (1984).
12. S. Lee and F. S. Chu, J. Assoc. Off. Anal. Chem., 64, 156 (1981).

13. H. Peters, M. P. Dierich and K. Dose, Hoppe-Seyler's Z. Physiol. Chem., 363, 1437 (1982).

14. C. J. Mirocha, S. V. Pathre and J. Behrens, J. Assoc. Off. Anal. Chem., 59, 221 (1979).

15. A. Visconti and F. Palmisano, J. Chromatogr., 252, 305 (1982).

16. H. J. C. F. Nelis and J. E. Sinsheimer, Anal. Biochem., 115, 151 (1981).

17. A. Sano, Y. Asabe, M. Suzuki and S. Takitani, Bunseki Kagaku, 32, E93 (1983).

18. A. Sano, Y. Asabe and S. Takitani, Bunseki Kagaku, 32, E37l (1983).

19. F. Kröhnke, K. Ellegast and E. Bertram, Liehigs Ann. Chem., 600, 198 (1956).

20. J. M. Bobbitt and R. E. Doolittle, J. Org. Chem., 29, 2298 (1964).

21. H. Cohen and M. Lapointe, J. Assoc. Off. Anal. Chem., 65, 1429 (1982).

(Received July 30, 1985) (Accepted August 24, 1985) 